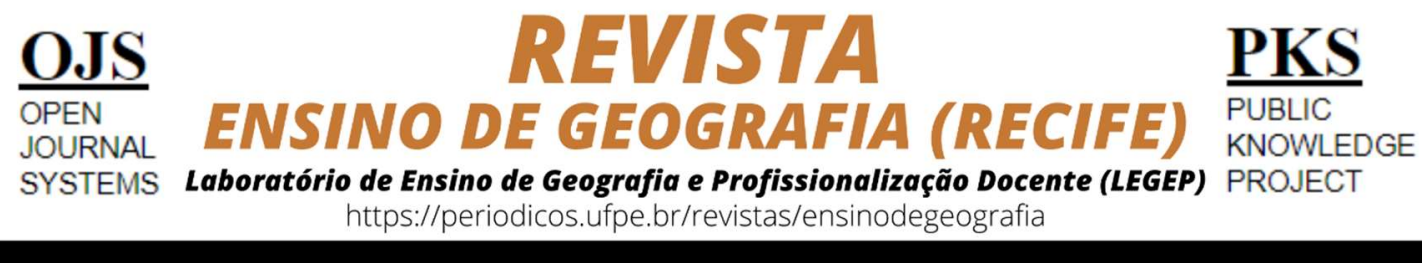

\title{
MONTE SEU MAPA: \\ UMA ATIVIDADE PARA A ALFABETIZAÇÃO CARTOGRÁFICA DE ALUNOS SURDOS
}

\author{
Tuane Telles Rodrigues ${ }^{1}$, Letícia Ramires Corrêa Correio ${ }^{2}$ \\ ${ }^{1}$ Doutoranda em Geografia no Programa de Pós-graduação em Geografia (PPGGeo) da Universidade \\ Federal de Santa Maria (UFSM), E-mail: tuanytel@hotmail.com \\ 2 Doutoranda em Geografia no Programa de Pós-graduação em Geografia (PPGGeo) da Universidade \\ Federal de Santa Maria (UFSM), E-mail: leticiarcorrea@gmail.com
}

Artigo recebido em 18/12/2019 e aceito em 07/04/2020

\begin{abstract}
RESUMO
Os recursos digitais educacionais, alinhados às novas propostas de modernização tecnológica nas escolas, têm sido amplamente discutidos e utilizados no ensino de Geografia. É nesse contexto que apresentamos a atividade Monte seu Mapa, concebida no jogo digital educacional denominado "CartoCon: Nossa Expedição Geográfica". Ela tem como enfoque a alfabetização cartográfica, seja de alunos surdos e deficientes auditivos, ou alunos ouvintes de Santa Maria. Assim, o presente artigo tem como objetivo apresentar a construção da atividade e seu uso por parte de alunos em uma oficina educativa realizada para esse fim. A metodologia utilizada percorre a parte de organização e planejamento da atividade, bem como sua aplicação com duas turmas de ensino fundamental, compostas por alunos surdos e deficientes auditivos de uma escola de educação especial de Santa Maria/RS. Como resultado, discutimos a atividade finalizada e a percepção dos alunos ao utilizar a ferramenta para praticar os conteúdos cartográficos trabalhados teoricamente.
\end{abstract}

Palavras-chave: Ensino de Geografia; Cartografia Escolar; Mapa.

\section{RIDE YOUR MAP: AN ACTIVITY FOR CARTOGRAPHIC LITERACY OF DEAF}

\begin{abstract}
Educational digital resources, aligned with the new proposals for technological modernization in schools, have been widely discussed and used in the teaching of geography. It is in this context that we present the activity Monte seu Mapa, conceived in the educational digital game called "CartoCon: Our Geographic Expedition". It focuses on cartographic literacy, whether deaf and hard of hearing, or hearing students of Santa Maria. Thus, this article aims to present the construction of the activity and its use by students in an educational workshop held for this purpose. The methodology used covers the organization and planning of the activity, as well as its application with two elementary classes, composed by deaf and deaf students from a special education school in Santa Maria / RS. As a result, we discuss the finalized activity and the students' perception when using the tool to practice the theoretically worked cartographic contents.
\end{abstract}

Keywords: Geography teaching; school cartography; map. 


\section{Introdução}

Importante para o estudo dos conteúdos geográficos na escola, a Cartografia Escolar envolve a possibilidade de espacializar informações através de mapas temáticos e representações apresentadas em diferentes escalas. As discussões sobre a pertinência da Cartografia para o desenvolvimento do pensamento geográfico vêm se tornando cada vez mais capilarizadas no meio acadêmico. Busca-se a transformação, a modernização (teórica, prática e metodológica), e o desenvolvimento de aspectos inclusivos nesta área tão relevante da educação geográfica.

A capacidade de leitura e a interpretação de mapas, assim como o desenvolvimento da criticidade dos sujeitos acerca da realidade, são objetivos da Cartografia Escolar. É fundamental, nessa área, proporcionar aos alunos a capacidade de se tornarem mapeadores críticos e conscientes. Existem softwares especializados na construção de representações cartográficas. Entretanto, tais ferramentas nem sempre são os recursos mais adequados, tendo em vista as finalidades da atividade pedagógica e os recursos cognitivos exigidos para o seu manejo, que podem pressupor o cumprimento de um número maior de estágios da vida escolar. Para alunos surdos e deficientes auditivos, esses instrumentos de mapeamento podem se tornar ainda mais difíceis, uma vez que não utilizam a Libras como meio de comunicação. Nesse contexto, é possível fazer uso de programas básicos para a organização de elementos que constituem os mapas, mais acessíveis aos alunos, a exemplo da atividade "Monte seu Mapa".

Construído como atividade final do jogo digital "CartoCon: Nossa Expedição Geográfica", o "Monte seu Mapa" reúne os principais elementos envolvidos nas representações cartográficas. Com ele, pudemos trabalhar temas de Cartografia Escolar com alunos surdos e deficientes auditivos da Escola de Educação Especial Dr. Reinaldo Fernando Cóser, localizada no município de Santa Maria/RS.

O presente artigo tem como objetivo falar sobre a construção da atividade "Monte seu Mapa", desde a organização até a inserção no jogo digital, apontando características primordiais para a organização dos mapas de Santa Maria e municípios lindeiros e a sua utilização por parte dos alunos. Nesse sentido, esperamos que o projeto desenvolvido possa contribuir com as discussões sobre métodos e materiais voltados ao ensino de Geografia no contexto da inclusão escolar. Pensamos que a democratização das práticas pedagógicas é um objetivo a ser perseguido pelas pesquisas. 


\section{Apoio teórico}

Segundo Callai (1986), para que seja possível promover o aprendizado em Geografia e torná-lo interessante aos alunos, independentemente de recursos mediadores, é necessário superar alguns desafios, como saber o que queremos ao ensinar, tendo claro o caminho que seguiremos para obter êxito, e conhecer da forma mais completa possível o espaço a ser estudado e ensinado. De acordo com esse raciocínio, o sucesso do professor ocorre quando os alunos compreendem de forma significativa o espaço e as dinâmicas sociais que nele se articulam. Para que isso ocorra da melhor forma possível, é importante valorizar o aprendizado próprio dos alunos, cabendo a nós, professores, auxiliar na ampliação dos seus conhecimentos e interpretações pessoais, estabelecendo conexões com os saberes já produzidos.

O uso de recursos didáticos como ferramentas para a mediação entre teorias e aplicações no ensino de Geografia é algo interessante, pois são instrumentos que fazem parte do ambiente escolar, auxiliando concretamente os processos de ensinoaprendizagem. Nesse sentido, temos a finalidade de facilitar a compreensão dos alunos, seja mediante os tradicionais livros de exercícios de fixação, mapas, ilustrações ou uso de técnicas multimídia, como filmes, apresentações de slides, ou mediante o uso de computadores, com os quais a gamificação torna-se uma ferramenta.

Alguns estudiosos sugerem que o uso adequado dos recursos e técnicas possibilita sensibilizar o aluno para o conteúdo ministrado, a exemplo de Souza (2010), que afirma que isso pode colaborar com o desenvolvimento da capacidade de observação, motivar o interesse do aluno, desenvolver a experimentação concreta, fixar a aprendizagem, e consolidar os conteúdos da aprendizagem. Segundo Pontuschka (2007, p.216), “os recursos didáticos na qualidade de mediadores do processo de ensino-aprendizagem, se adequadamente utilizados, permitem melhor aproveitamento neste processo, maior participação e interação aluno-aluno e professor-aluno".

Discutimos até aqui algumas questões teóricas e práticas sobre o ensino de Geografia em âmbito escolar, mas uma temática que não pode faltar é a questão dos instrumentos de avaliação de aprendizagem, assunto de relevância pedagógica inclusive na realização desta pesquisa, em pontos em que foi necessário propor uma estratégia de avaliação de desempenho dos alunos, de forma quantitativa e qualitativa. Pois, como salienta Libâneo (1994, p. 195), essa é uma "tarefa didática necessária e permanente do 
trabalho docente, que deve acompanhar passo a passo o processo de ensino e aprendizagem". Certamente devemos considerar, em todos os contextos escolares, as individualidades e vivências dos alunos, mesmo que para tanto tenhamos recursos nem sempre ideais.

A gamificação está presente em muitas situações de aprendizagem. Os exemplos mais notórios são a atribuição de recompensas por participação em atividades realizadas - forma de presentear os alunos pelo empenho demonstrado - e o uso de tecnologias como o Moodle (uma plataforma de acesso livre utilizado como recurso de apoio à aprendizagem em ambiente virtual), utilizadas por diversas instituições de ensino do país e que possibilitam propor atividades que estimulam o acesso e a interatividade dos discentes, fazendo uso de elementos de gamificação, superando os tradicionais questionários.

Contudo, de acordo com Nicholson (2012), uma boa parte dos recursos das gamificações se caracteriza pelo uso simples de pontos, medalhas e rankings de líderes, sem comprometimento com uma visão da aprendizagem a longo prazo. $\mathrm{O}$ autor expõe as críticas feitas por aqueles que estudam os jogos aplicados à educação. Segundo eles, o termo "jogo" (game) como prefixo de gamification revela-se negativo por estimular a expectativa de que toda a atividade será uma experiência envolvente, quando na realidade a gamification envolve partes menos interessantes de um jogo, como o sistema de pontuação. Da mesma forma, Deterding (2012) alerta que os desenvolvedores que acreditarem que "gamificar" é a simples adição de recompensas e incentivos com pontos e medalhas dentro de um sistema estão destinados a fracassar em suas aplicações. Entretanto, contrapomos a afirmação do autor, pois ele desconsidera o papel mediador do professor, e da capacidade qualificadora de avaliar a aprendizagem dos alunos ao utilizarmos estes elementos de recompensa, ou ao estabelecer um sistema de pontos com base nos acertos dos alunos. Nesse sentido, na atividade "Monte seu Mapa", buscamos introduzir elementos de gamificação (como pontuação e ranqueamento) como uma forma de que o aluno tenha seu aprendizado avaliado pelo professor, ao mesmo tempo em que o sujeito se utiliza de outras habilidades, tais como: abstração, orientação, organização, categorização, entre outros, para a realização da atividade.

Podemos ver a gamificação presente desde a construção de atividades avaliativas em plataformas de ensino e aprendizagem, a exemplo do Moodle UFSM que possui atividades como "sopa de letras", "palavras-cruzadas", entre outros, até a construção de jogos propriamente concebidos como ferramentas de aprendizagem, ou seja, jogos 
educacionais, até em. O “CartoCon: Nossa Expedição Geográfica”, jogo produzido durante a nossa pesquisa, é um recurso que adota estratégias para prolongar o interesse dos alunos, como um sistema de recompensas inserido em cada atividade cumprida, e que ao final das tarefas, fornece aos alunos um conceito que pode ser superado a cada nova jogada. Além disso, o próprio fato de ser um jogo pode despertar nos alunos o interesse de ser um jogador, fazendo com que eles não se vejam apenas como quem está realizando uma atividade avaliativa. Outro fato relevante é que o uso de uma plataforma que utilize um cenário conhecido pelos alunos (o centro de Santa Maria, no nosso exemplo) tende a aproximar o recurso da realidade dos alunos.

Os jogos digitais educacionais são mobilizados sob duas relações importantes: a relação dinâmica, de onde partem as interações entre o jogador e as mecânicas de jogo, e compõem os aspectos gerais da gamificação, devendo ser gerenciadas em sua estrutura; e a relação mecânica, que são os elementos específicos que coordenam às ações pontuais do jogador, e que orientam os jogadores a utilizá-las como em uma direção desejada, estabelecendo o limite, na estrutura do jogo, daquilo que o jogador pode ou não fazer. Diversos mecanismos podem estar inseridos na dinâmica, como feedback e recompensas que podem, de fato, caracterizar a gamificação, através de uma matriz de referência de progressão no jogo.

Pensamos que as ferramentas digitais podem ser um interessante apoio ao professor, já que podem ser concebidas tendo em vista a inclusão escolar, o que fomenta muitas pesquisas. Alinhadas à realidade de muitos alunos no Brasil, as estratégias que utilizam tais ferramentas possibilitam a incursão tecnológica no campo educacional, modernizando práticas e buscando aproximar os alunos dos conteúdos escolares, uma vez que consideram as transformações informacionais presentes no cotidiano dos discentes. Com estratégias inclusivas é possível transformar e formar alunos autônomos frente às tecnologias educacionais. Para Galisi (2009):

\footnotetext{
"Um jogo é um objeto que se assemelha a muito outros, mas possui as suas especificidades; sendo assim, tem a sua própria metodologia de desenvolvimento. Ele se assemelha a um website, pelo fato de possuir uma interface digital e visual, mas um website não tem elementos fundamentais para o sucesso de um videogame, como regras e estratégias de jogos; é similar a um filme, pois, em muitos casos, apresenta cenário, personagens e roteiro, mas, até que se prove o contrário, o cinema é um meio cuja estrutura (quadro a quadro) é linear e cuja interação é pouco participativa, no que diz respeito à construção da narrativa por parte do usuário. Desenvolver um jogo é, muitas vezes, parecido com construir um software aplicativo, mas esta é uma ferramenta, e o jogo é um produto de entretenimento e cultura (GALISI, 2009, p. 234)".
} 
Percebemos que os jogos digitais chamam a atenção dos sujeitos, sejam crianças, adolescentes ou adultos. A aplicação dessa metodologia nas aulas de Geografia é uma forma de levar o educando a estudar de maneira prazerosa. Segundo Rego (2000, p.79):

"[...] ambientes desafiadores, capazes de "estimular o intelecto"
proporcionando a conquista de estágios mais elevados de raciocínio isso quer
dizer que o pensamento conceitual é uma conquista que depende não somente
do esforço individual, mas principalmente do contexto em que o indivíduo se
insere que define, aliás, seu ponto de chegada (REGO, 2000, p. 3)".

O uso das tecnologias como ferramentas no ensino encolar é algo apreciado em outros países do mundo, a exemplo do capítulo chamado de "Technologies de l'information et de la communication dans les systèmes éducatifs en Europe: Politiques éducatives nationales, programmes d'enseignement, formation des enseignants", apresentado no relatório "Les chiffres clés de l'éducation en Europe", realizado pela União Europeia do Eurydice (Rede de informação sobre a educação na Europa), publicado em 2000, em que é apresentada uma perspectiva global sobre as políticas educativas nacionais de vinte e nove países europeus em referência às Tecnologias de Informação e Comunicação (TIC).

Silva (2004) diz que o uso de jogos em situações-problema contribui para o ensino, conferindo ao aluno um papel ativo na construção dos novos conhecimentos, pois permite, com o objeto a ser conhecido, incentivar a troca e a coordenação de ideias e hipóteses diferentes. De acordo com Gioca (2001) os jogos constituem importante recurso, que favorece o domínio das habilidades em comunicação e expressão. Para ele, essas ferramentas pedagógicas encorajam o desenvolvimento intelectual por meio do exercício da atenção e pelo uso progressivo de processos mentais mais complexos, como comparação, discriminação e imaginação.

Goldfeld (2002, p.79) diz que outros tipos de jogos são os jogos limítrofes, “que marcam o limite entre os brinquedos da pré-escola e a atividade lúdica do período escolar". O uso de jogo digitais em uma determinada etapa de maturação cognitiva tendencia o progresso do pensamento lógico e do raciocínio contextual que o recurso possibilita.

Oliveira (2009) garante que os jogos educativos em ambiente eletrônico podem trazer benefícios às crianças surdas no que se refere à aprendizagem, sendo que por

\footnotetext{
1 “Tecnologias de Informação e Comunicação nos sistemas educativos na Europa: Políticas educativas nacionais, programas de ensino, formação de professores".

2 "Números chave da educação na Europa".
} 
meio deste recurso o aluno pode desenvolver algumas habilidades que a falta da audição compromete. Isso é explicado por Tarouco (2008), ao dizer que os jogos virtuais aumentam as conexões neurais, e alteram o fluxo sanguíneo no cérebro em razão da exigência de concentração.

Assim, as tecnologias aplicadas à educação podem configurar uma metodologia própria, digital e informatizada, que pode contribuir para a preparação dos alunos, não apenas para os temas que passam a ser desenvolvidos dentro da proposta de cada ambiente digital, mas também para que o próprio ambiente proporcione uma inovação nas formas de aprender. Cezar (2009, p. 38) alega que o jogo é uma atividade que interfere diretamente no desenvolvimento da imaginação, da representação simbólica, dos sentimentos, do prazer, das relações, do movimento, da autoimagem e do desenvolvimento cognitivo. Portanto, é possível considerar que a busca pelo aperfeiçoamento das técnicas na educação é parte importante da construção dos saberes, podendo contribuir para o aprendizado do saber geográfico.

\section{Metodologia}

A atividade intitulada "Monte seu Mapa" foi planejada e concebida com o objetivo de reunir todos os conceitos e conteúdos trabalhados ao longo do jogo digital "CartoCon: Nossa Expedição Geográfica"3, razão pela qual foi apresentada ao final das atividades. Nela, o aluno pode montar um mapa de localização de Santa Maria ou de seus municípios lindeiros, sendo possível também personalizá-los. Colocamos à disposição os recortes dos municípios São Martinho da Serra, Itaara, Júlio de Castilhos, Silveira Martins, São João do Polêsine, Restinga Sêca, Formigueiro, São Sepé, São Gabriel, Dilermando de Aguiar e São Pedro do Sul. Para obter os polígonos de cada município, fizemos uso de arquivos pessoais em shapefile, utilizados em programas específicos para a confecção de mapas, que ao serem exportados individualmente adotam o formato de imagem Portable Network Graphics (PNG). Independente de características particulares de cada município, a escolha deles ocorreu em face da relação dos alunos com os municípios. Muitos deles são migrantes pendulares, pois vão à Santa Maria para estudar na escola Cóser e retornam ao final da tarde para seus municípios de origem, como Itaara e Silveira Martins. A figura 1 apresenta os municípios agregados, que fazem parte das bases cartográficas empregadas na atividade.

\footnotetext{
${ }^{3}$ Disponível em: https://tuanytel.wixsite.com/cartografiaescolar
} 
Figura 1 - Mapa dos municípios disponíveis na atividade

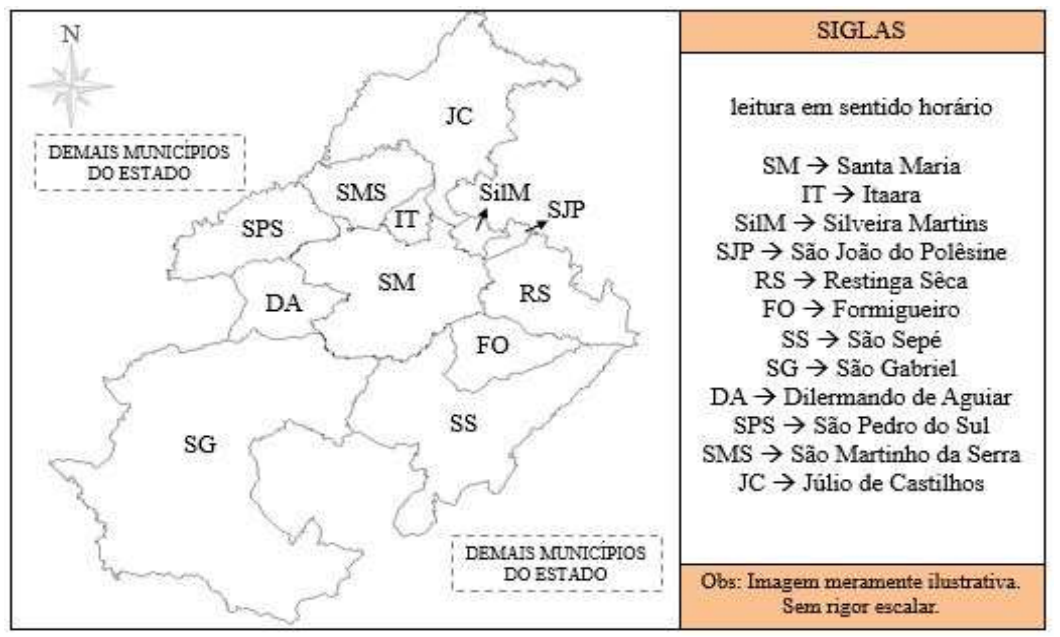

Fonte: autoras (2019).

A interface da atividade apresenta um formato padrão para a apresentação de mapas, iniciando em representações de menor escala (normalmente utilizadas como princípio para a localização), seguindo para recortes espaciais com escalas maiores, que chegam ao espaço de estudo específico. Nesse sentido, todos os mapas que o aluno escolhe têm como base de localização desde a América do Sul até o município de interesse.

Durante o percurso do jogo, cuja movimentação ocorre através do Cursor Control Keys ${ }^{4}$, as atividades previamente programadas foram apresentadas por meio de um objeto, uma moeda dourada, que quando ativado apresenta o exercício cartográfico. Assim, o jogo deve envolver os seguintes conteúdos fundamentais ao processo de alfabetização cartográfica: orientação, escala, coordenadas geográficas (com pontos marcados e apresentados nos locais dos finais de percurso) e ter acesso às representações (carta, mapa e planta). Neste caso, a carta apresentada é a de Camobi (folha SH.22-V-C.2; MI-2965/2; escala 1:50.000), com o recorte da delimitação por onde o educando percorrerá o trajeto.

Ao término do mapa, o educando poderá imprimir seu desenho finalizado (ou não, já que há liberdade de encerrar o jogo a qualquer momento), onde entre informações básicas, aparece também o total de pontos obtidos pela soma das atividades realizadas. Isso ocorre com o intuito de possibilitar uma posterior avaliação pessoal ou docente, caso o professor se interesse em analisar quantitativamente o desempenho do aluno.

\footnotetext{
${ }^{4} \mathrm{O}$ Cursor Control Key está presente no teclado indicados com as setas nas quatro direções.
} 
Esperamos que com isso os alunos aprendam não apenas a interagir com os elementos constituintes dos mapas, mas que possam aprender o processo de confecção das representações, o pensamento crítico, artístico, e o entendimento técnico do processo de cartografar. A seguir, a figura 2 mostra como a atividade "Monte seu Mapa” está organizada.

Figura 2 - Planejamento do compositor

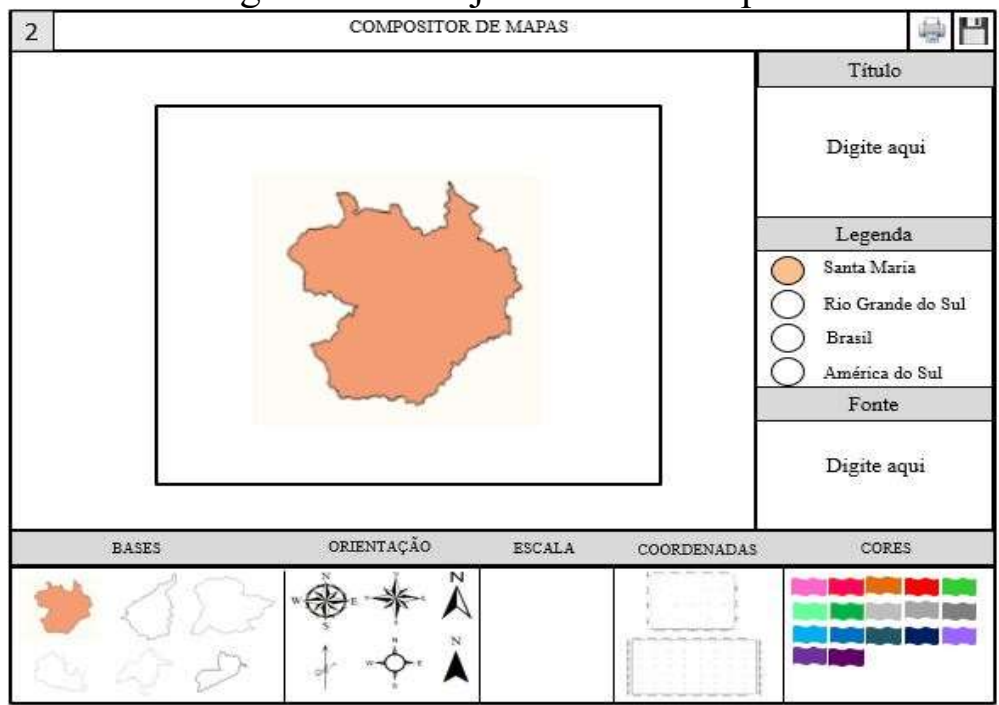

Fonte: autoras (2019).

É possível perceber na figura 2 que está disponível aos alunos, na barra lateral direita, um menu de identificação com três itens: o título, onde o usuário é capaz de identificar seu mapa, apresentando seu tema; a legenda, onde após a escolha das cores dos polígonos, a legenda aparece de forma automática com as cores correspondentes; e a fonte, onde os alunos podem identificar o autor do mapa com seu nome. Acima da barra lateral, encontram-se duas ações importantes, uma que permite a impressão do mapa e outra que permite salvá-lo na mesma pasta em que o jogo digital se encontra.

Ainda na figura 2, temos uma barra lateral que comportam elementos como: as bases cartográficas principais (América do Sul, Brasil e Rio Grande do Sul e municípios), orientação (representada por diferentes imagens de nortes geográficos), escala (numérica e gráfica), coordenadas (geográficas ou Universal Transversa de Mercator), e um paleta de cores para personalizar os mapas.

Na figura 3 temos a versão final do mapa, mostrando desde a representação criada até as informações dos autores. No rodapé do mapa, aparecem informações adicionais, passíveis de avaliação por parte dos professores sobre o desempenho dos alunos, divididas em: pontos na atividade, pontos totais (que reúne a pontuação obtida em todo jogo digital), e o título que o aluno recebeu. Tais informações estão associadas 
às características da gamificação, em que os alunos são condecorados por seu desempenho no jogo digital através do uso de conceitos com base no cálculo que considera o número de acertos e a quantidade de tempo que o aluno levou para responder cada questão.

Figura 3- Versão final do compositor de mapas

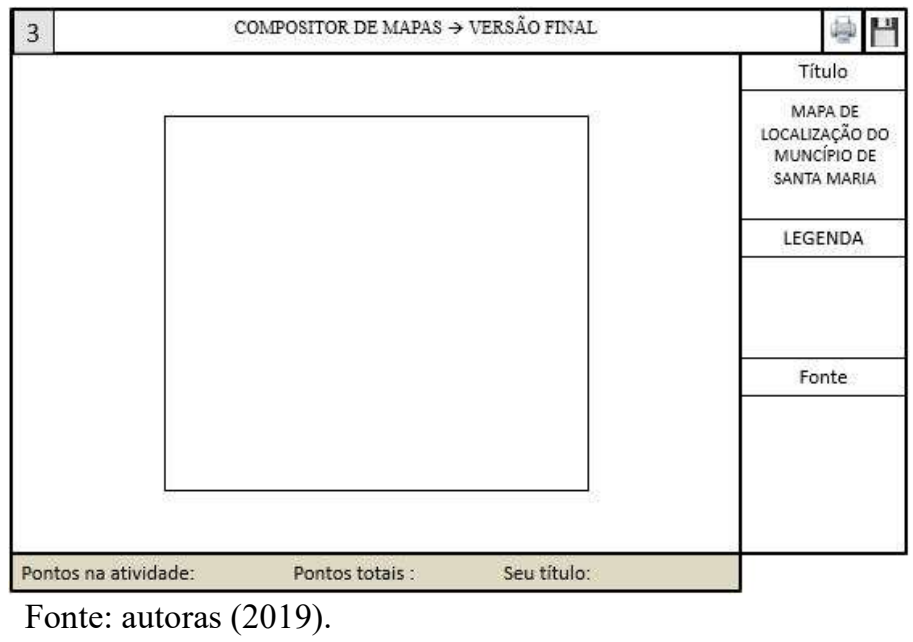

Após a finalização da atividade, levamos o jogo digital para a avaliação dos alunos da escola. Ao todo foram quinze participantes, sendo cinco alunos de sexto ano (três surdos e dois deficientes auditivos), quatro alunos do sétimo ano (ambos surdos), seis alunos de oitavo ano (cinco surdos e um deficiente auditivo). Após a finalização do jogo, na atividade final, puderam os alunos interagir na posição de mapeadores. Ainda que o jogo seja uma simples organização de informações, os alunos puderam praticar conhecimentos conceituais sobre conteúdos mais importantes aplicados à arte de concepção de mapas. Ao final da atividade, dialogamos com os alunos sobre suas experiências, com o objetivo de analisar a validade da atividade enquanto recurso pedagógico na alfabetização cartográfica. Esse diálogo foi mediado pela professora da classe, que realizou as traduções em Libras para o português. Inicialmente, ainda na etapa de planejamento do contato com os alunos, sugerimos a aplicação de um questionário com o mesmo objetivo. No entanto, a professora avisou que muitos dos alunos, apesar da idade, estariam em processo de alfabetização da língua portuguesa, uma vez a língua prioritariamente utilizada é a Libras.

\section{Resultados}

O primeiro resultado obtido refere-se à construção da atividade. Como já mencionado, ela é parte integrante do jogo digital CartoCon: Nossa Expedição Geográfica. A programação do jogo como um todo, incluído o "Monte seu Mapa", 
contou com a parceria de uma empresa privada de Porto Alegre, que executou toda a complexa parte estrutural. A possibilidade de aplicar de forma prática o conhecimento teórico em desenvolvimento teve como premissas a concretização de uma representação cartográfica e a organização dos elementos que as compõem, com a finalidade de auxiliar os alunos a se tornarem mapeadores conscientes de sua realidade. A figura 4 mostra a atividade disponível no jogo:

Figura 4- A atividade "Monte seu Mapa"

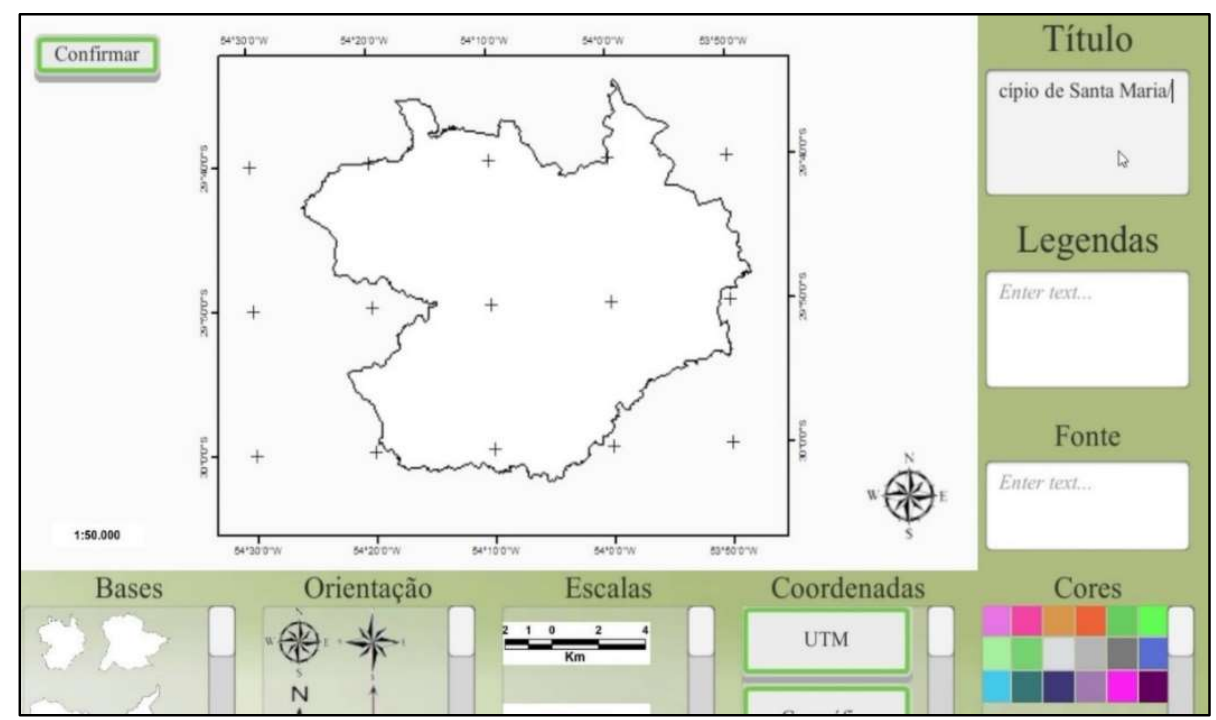

Fonte: autoras (2019).

Bem recebida pelos alunos, a atividade "Monte seu Mapa" cumpriu com êxito seu objetivo. Isso se deve, como pudemos observar, a três fatores: a forma como os mapas estão organizados, que por serem apresentados de forma clara e limpa facilitam a compreensão dialógica entre as representações; a presença de todos os elementos que constituem o mapas e possibilitam a construção de verdadeiras representações cartográficas; a utilização do município em que os alunos residem, o que proporciona integração do sentimento de pertencimento àquele território.

O diálogo com os alunos teve três temas principais. O primeiro foi sobre a jogabilidade, para sabermos se houve algum bug durante a execução da atividade. Tal possibilidade normalmente está associada à memória do computador ou a uma versão de sistema operacional mais antiga. Porém, graças à boa estrutura do laboratório de informática da escola (onde a atividade foi realizada), o jogo transcorreu de forma satisfatória, fluída, e sem a necessidade do programa Unity ${ }^{5}$ (responsável pela execução

\footnotetext{
5 o software Unity (versão 2017) para a montagem e compilação dos elementos do jogo, ou seja, o ambiente que integralizou todos os objetos construídos nas plataformas anteriores. O programa encontrase disponível para download nas versões livre (com algumas limitações) e por assinatura, com os recursos
} 
do game) abstrair algum elemento do jogo como forma de permitir a jogabilidade. A figura 5 mostra os alunos interagindo com a atividade.

Figura 5- Alunos interagindo com a atividade

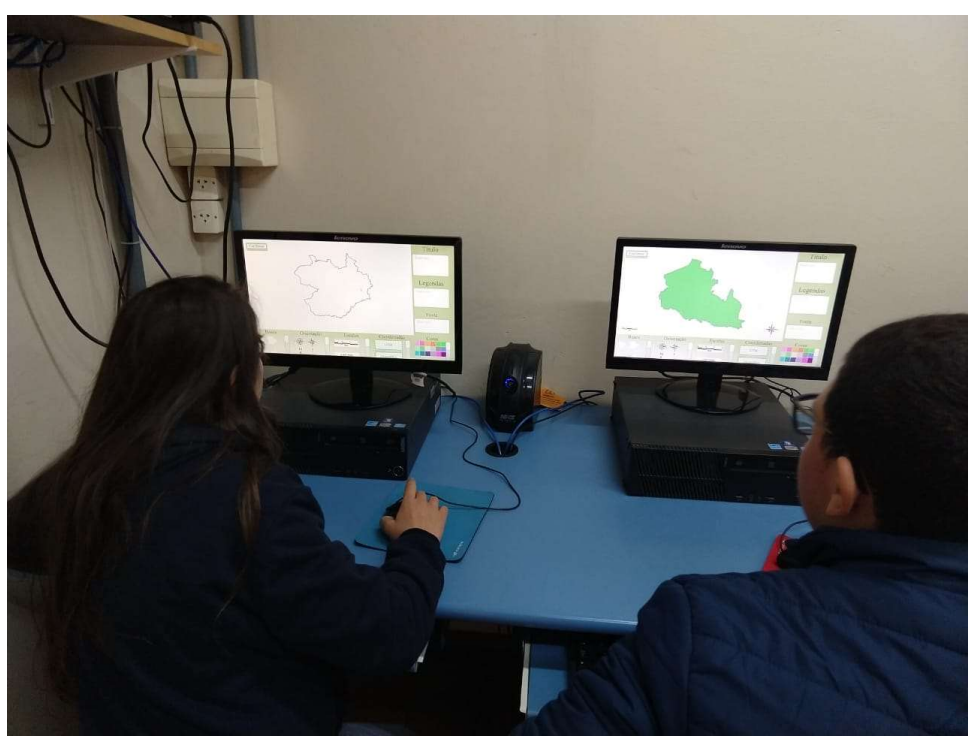

Fonte: autoras (2019).

O segundo tema envolveu a aplicação dos conteúdos cartográficos no mapa. Até então, nenhum dos alunos havia utilizado qualquer tipo de programa voltado para tal fim. Com isso, doze alunos disseram ter conseguido organizar a representação de forma simples, uma vez que os conteúdos haviam sido anteriormente trabalhados no jogo digital, e que por este motivo, a etapa de aplicação dos elementos constituintes do mapa contribuiu para o entendimento da importância que esses conteúdos têm no mapeamento e na interpretação posterior das imagens. Apenas dois alunos do sexto ano expressaram dificuldade em saber como proceder com a organização. Dentre esses, havia um com diagnóstico de Transtorno do Déficit de Atenção e Hiperatividade, o que pode ter contribuído para a dificuldade. O outro aluno se disse pouco interessado em realizar a atividade.

O terceiro tema objeto de discussão foi o recurso e suas possibilidades para a Cartografia Escolar. Com isso, esperamos entender a validade da atividade como ferramenta para o processo de alfabetização cartográfica. Nesse sentindo, os alunos, de modo geral, mostraram-se empolgados com o uso da atividade (apenas um deles, como

completos. O programa é chamado também de Build Standalone, o que significa que o jogo é gerado independentemente do usuário dispor ou não do programa Unity pré-instalado em seu computador. É importante destacar que o programa executa apenas no sistema Windows, não estando possível em outros sistemas operacionais, como as distribuições Linux e o Mac OS. 
mencionado anteriormente, não se sentiu motivado, o que não exclui a questão da aprendizagem desenvolvida), todos disseram conseguir articular melhor os conhecimentos teóricos e práticos, sabendo como ocorre a etapa de mapeamento.

Assim, concluímos as duas etapas apresentadas. Com a confecção da atividade e com a verificação qualitativa da percepção dos alunos, entendemos que a atividade "Monte seu Mapa" pode ser um recurso pertinente ao ensino de Geografia no contexto inclusivo.

\section{Conclusão}

A atividade Monte seu Mapa mostrou-se adequada ao processo de alfabetização cartográfica de alunos surdos e deficientes auditivos do município de Santa Maria/RS. Diante das repostas positivas que obtivemos por parte dos alunos, podemos concluir que atividades semelhantes que busquem integrar conteúdos cartográficos e oportunizar aos alunos o papel de mapeadores, mediante instrumentos de análise do espaço e suas dinâmicas, são fundamentais para o ensino de Geografia.

A criação de recursos educacionais em modelos digitais pode promover o acesso e a autonomia dos alunos. Quando conduzidas de forma inclusiva, estas ferramentas são capazes de promover a modernização das práticas em sala de aula, e alinham-se ao cotidiano de muitos alunos, que veem nas tecnologias uma forma de interação e integração social e educacional.

Destacamos também a importância da criação de ferramentas voltadas para a análise do espaço. Ferramentas essas criadas de forma apropriada ao desenvolvimento cognitivo dos alunos, como softwares que promovam e dinamizem as práticas em sala de aula, e que se estendam às práticas dos alunos em casa.

\section{Considerações Finais}

O presente artigo buscou mostrar a importância de uma atividade prática digital como instrumento favorecedor da compreensão dos alunos - no nosso caso, alunos surdos e deficientes auditivos - acerca dos conteúdos básicos para o mapeamento. Para isso, consideramos importante a utilização de ferramentas contemporâneas para a análise do espaço e o desenvolvimento crítico do pensamento geográfico.

Ainda que a atividade "Monte seu Mapa" permita exclusivamente a organização de informações cartográficas com o objetivo de gerar um mapa de localização simples, o contato com uma ferramenta que possibilite colocar os alunos no papel de mapeadores mostra-se relevante para a alfabetização cartográfica. A aplicabilidade de 
conhecimentos obtidos de forma teórica faz com que os alunos efetivem a compreensão de como tais informações se articulam, fixando, dessa forma, os conteúdos e possibilitando leituras e interpretações cada vez mais aguçada de representações do espaço inseridas no contexto da Cartografia.

\section{Referência Bibliográfica}

CALLAI, Helena C. Educação Geográfica: teorias e práticas docentes. $2^{\circ}$ ed. Ijuí: UNIJUÍ, 1986.

CEZAR, Kelly Priscilla L. Acentolândia: criação e aplicações de um jogo de regras sobre acentuação gráfica para séries iniciais do ensino fundamental. Maringá: 2009.

DETERDING, S. Gamification: designing for motivation. Interactions, v.19, n. 4, p. 14-17, jul./ago. 2012. Disponível em: <http://dx.doi.org/10.1145/2212877.2212883>. Acesso em: 05 dez. 2018.

EURYDICE. Technologies de l 'information et de la communication dans les systèmes éducatifs en Europe. Politique éducatives nationales, programmes d 'enseignement, formation des enseignants. Extrait du rapport: Les chiffres clés de l'éducation en Europe. Bruxelles: URYDICE, 2000.

GALISI, D. Videogames: ensino superior no Brasil. In: SANTAELLA, Lucia; FEITOZA, Mirna (Org.). Mapa do jogo: a diversidadecultural dos games. São Paulo: Cengage Learning, 2009.

GIOCA, M. I. O jogo e aprendizagem na criança de 0 a 6 anos. Trabalho de conclusão de curso. Belém - Pará: Universidade da Amazônia. 2001.

GOLDFELD, M. A Criança Surda: Linguagem e Cognição Numa Perspectiva Sociointeracionista. 2ed. São Paulo: Plexus Editora, 2002.

LIBÂNEO, J.C. Didática. São Paulo: Cortez, 1994.

NICHOLSON, S. A user-centered theoretical framework for meaningful gamification. In: Games Learning Society. n², 2012, MADISON, W. 2012. p. 1-7. Disponível em: $<$ http://scottnicholson.com/pubs/meaningfulframework.pdf $>$. Acesso em: 05 dez. 2018.

OLIVEIRA, A. C. M. T. G. de. Proposta de desenvolvimento de um jogo eletrônico educativo para crianças com deficiência auditiva. Garça: CEETEPS-FATEC, 2009.

PONTUSCHKA, N. N.; PAGANELli, T. L.; CACETE, N. H. Para ensinar e aprender Geografia. São Paulo: Cortez, 2007.

REGO, T. C. Vygotsky: Uma Perspectiva Histórico - cultural da educação. Petrópolis: Editora Vozes, 2000.

SILVA, A. A. T. Ensinar e aprender com as Tecnologias. Tese de doutorado. Instituto de Educação e Psicologia, Universidade do Minho. Braga, 2004.

SOUZA, A. de. Didática e Prática do Ensino de Geografia. Indaial: Grupo UNIASSELVI, 2010.

TAROUCO, L. M. Jogos Educacionais, Novas Tecnologias na Educação. CINTEDUFRGS. 2008. 